\title{
PREPARATION OF LEMONGRASS OIL MICROCAPSULES FOR APPLICATION ON HEALTHCARE PRODUCTS
}

\section{MEENU SRIVASTAVA ${ }^{1} \&$ KALINDRI VERMA ${ }^{2}$}

Department of Textiles \& Apparel Designing, College of Home Science, MPUAT, Udaipur(Raj.), Rajasthan, India

ABSTRACT
Present paper is part of the research outcome conducted on development of multifunctional finishes on cotton
fabric using selected herbal extracts. Lemongrass oil was selected by the researcher for conducting laboratory
experiments on the preparation of lemongrass oil microcapsules using conservation techniques by optimizing the different
variables involved in the microencapsulation process. The resultant precipitate obtained after each process was analyzed
under an inverted microscope to ensure the formation of microcapsules and images were captured. The findings of the
study revealed that best results of microcapsules formation using lemongrass oil were obtained when the ratio of oil: gum:
gelatin was kept 2:4:4, at an optimized $50^{\circ} \mathrm{C}$ temperature having initial pH 4.5 and final pH 9.5 .
KEYWORDS: Preparation, Microencapsules, Lemon Grass oil, Health, Care, Products

Received: May 13, 2017; Accepted: May 29, 2017; Published: Jun 29, 2017; Paper Id.: IJTFTAUG20171

\section{INTRODUCTION}

The use of natural ingredients in consumer products has a very long history. Apart from being a source of food, many plant species biosynthesize and accumulate extractable substances with economic and health importance. An essential oil is the volatile lipophilic component extracted from plants. Microencapsulation systems protect the essential oil from degradation and evaporation, and, at the same time, allow a sustained release. (Marcela, et.al. 2015) Essential oils have been used to improve the health and physical appearance of the human exterior, and to protect a body part against damage from the environment since ancient times in human history (Shaaban, et.al 2012, Yorgancioglu, et.al.2013, and Kedia, et.al.2015). The market sustainability of the each new product mainly depends on the raw material as well as functionality. A functional finishing decides the end-use of the products as well as enhanced the life of the products. (Ammayappan, et.al.2013)

Cymbopogon citratus (DC) Stapf (Poaceae), commonly known as lemongrass, is widely used in traditional and folk medicine. Its chemical composition includes Citral, geraniol, myrcene, limonene, citronella, borneol, neryl acetate, Z-caryophyllen (Kpoviessi, et. al 2014). Lemongrass essential oil has antimicrobial activity against a diverse range of microorganisms, including, yeasts, and Gram-positive and Gram-negative bacteria (Naik, et. al 2010). Indeed, lemongrass oil is effective against generalized anxiety disorder and epilepsy (Costa et. al. 2011).

Microencapsulation is a method in which tiny particles or droplets are surrounded by a coating wall, or are embedded in a homogeneous or heterogeneous matrix, to form small capsules (Gharsallaoui and others 2007; Calvo and others 2011). It can envelop a solid, liquid, or gaseous substance within another substance in a very small sealed capsule. The core material is gradually diffused through the capsule walls, thereby offering controlled 
release properties under desired conditions (Fang and Bhandari 2010). The shelf-life, biological activity, functional activity, controlled release, physicochemical properties, and overall quality of oils can also be enhanced. Spray-drying and coacervation are the most commonly used techniques for the encapsulation of oils. Briefly, microencapsulation can be defined as a process of building a functional barrier between the core and the wall material to avoid chemical and physical reactions and to maintain the biological, functional, and physicochemical properties of the core materials. (Bakry, (2016)

Present research focuses on the preparation of microcapsule gels by optimizing the microencapsulation process of volatile oil of lemongrass oil to protect and maintain its stability by conservation technique for its application as effective as a fragrance finish besides enhancing its other functional properties in developing various health care textile products at a later stage.

\section{MATERIAL AND METHODS}

The raw material used in this study was the essential Cymbopogon citratus, Lemon grass oil and coating materials such as gum Arabic, gelatin. Other materials used were dilute acetic acid, $0.4 \mathrm{~N}$ sodium hydroxide solution, gluteraldehyde aqueous solution and sodium sulphate solution.

\section{Selection of Essential Oil}

Essential oils are a complex liquid mixture of volatile, lipophilic and odoriferous compounds biosynthesized by living organisms, predominantly aromatic plants. Berger, (2007). Researcher procured lemon grass oil from the market, for the sake of purity and maintaining uniformity in quality parameter,

\section{Selection of Wall Material}

Gelatine was used as an encapsulating agent, as wall material to encapsulate the inner core material (oil). Preparation of microcapsules by coacervation method usually involves a combination of gelatine and a carboxyl bearing polymer. Gum Arabic, a polymer most widely used for complex coacervation with a gelatine was used in this process with other naturally occurring polymer and synthetic polymer compatible with cotton fabric and other ingredients in the microencapsulation process based on the past studies.

\section{METHOD}

\section{Selection of Microencapsulation Technique}

Out of the many physical and chemical techniques of microencapsulation i.e. solvent evaporation, polymerization, spray drying, pan coating, phase separation centrifugal extrusion etc. The phase separation -complex coacervation technique was selected for present study by the researcher on the basis of review and the suitability of the process to be carried out in the laboratory of the department. Gum acacia was taken as the wall material and essential oil as the core material. Gelatin is the common ingredient in all the processes of complex coacervation. The basic recipe (Teli, et.al, 2005) was followed to optimize the various concentrations of the raw material used in microencapsulation process.

\section{Preparation of Microcapsules by Optimization Process}

The researcher conducted laboratory experiments for optimization of microencapsulation process of selected lemon grass oil. The combination of ratio of oil, gum and gelatin, which produced best results was further subjected to optimization of the other variables. At a time, the ratio of only one variable was varied and other variables were kept constant. 
- Optimization of Ratio of Essential Oil: To optimize the ratio of essential oil, five different ratios of oil i.e. 0.5, 1.0, 1.5. 2.0, 2.5 were taken while other variables, i.e. gum, gelatin, temperature and $\mathrm{pH}$ were kept constant to carry out a microencapsulation process. The resultant precipitate obtained was analyzed under an inverted microscope to ensure the formation of microcapsules and optimization was done on the basis of the visual assessment of the microcapsules size, uniformity in size and distribution and wall of the microcapsules on a comparative basis. The ratio giving best results was selected for next stage of optimization.

- Optimization of Ratio of Gum: For determination of optimum ratio of gum, five different ratios of gum i.e. 1, 2, 3, 4 and 5 were taken with an optimized ratio of essential oils whereas the ratio of gelatin was kept constant along with all other variables. Microencapsulation was carried out and optimum ratio of gum was optimized on the basis of visual assessment.

- Optimization of Ratio of Gelatin: For determination of the optimum ratio of gelatin, five different ratios of gelatin i.e. 1, 2, 3, 4 and 5 were taken with an optimized proportion of oil and gum and all other variables were kept constant. Microencapsulation was carried out and optimum ratio of gelatin was optimized on the basis of visual assessment.

- Optimization of Temperature: For determination of optimum temperature for microencapsulation, the process was carried out at six different temperatures, i.e. $30,40,50,60$ and $70^{\circ} \mathrm{C}$ with an optimized ratio of oils, gum and gelatin and other variables were kept constant. Optimized temperature was selected on the basis of visual assessment.

- Optimization of Initial and Final pH: pH plays very important role in microencapsulation as it is responsible for phase separation which leads to capsule formation. For optimization of $\mathrm{pH}$, the optimized ratio of essential oil, gum and gelatin at an optimized temperature was set to initial $\mathrm{pH} 4.0,4.5,5.0,5.5,6.0,6.5$ and 7.0. The microencapsulation process was carried out till gel formation took place and then final $\mathrm{pH}$ was maintained at 7.0, $7.5,8.0,8.5,9.0,9.5$ and 10.0 with each initial $\mathrm{pH}$. The initial and final $\mathrm{pH}$ was optimized on the basis of visual assessment of microcapsule gel.

\section{RESULTS AND DISCUSSIONS}

Preparation of Microcapsule Gel

Microcapsule gel was prepared by mixing selected essential oil, gum acacia and gelatin using the complex coacervation technique and optimization of various variables, i.e. ratio of essential oil:gum:gelatin, temperature and $\mathrm{pH}$ were carried out to obtain the best results.

\section{Optimization of the Ratio of Essential Oils in Microcapsule Gel}

Essential oils form the core material of the microcapsules and is basically responsible for multifunctional properties. Microcapsule gel was prepared using different ratios of selected clove oil, i.e. 0.5, 1.0, 1.5, 2.0 and 2.5 keeping other variables constant.

The gel was observed under Inverted Microscope to ensure the presence of microcapsules. The ratio of essential oil was optimized on the basis of visual assessment on three parameters, i.e. size of microcapsules, uniformity in size and distribution and wall of microcapsules. 

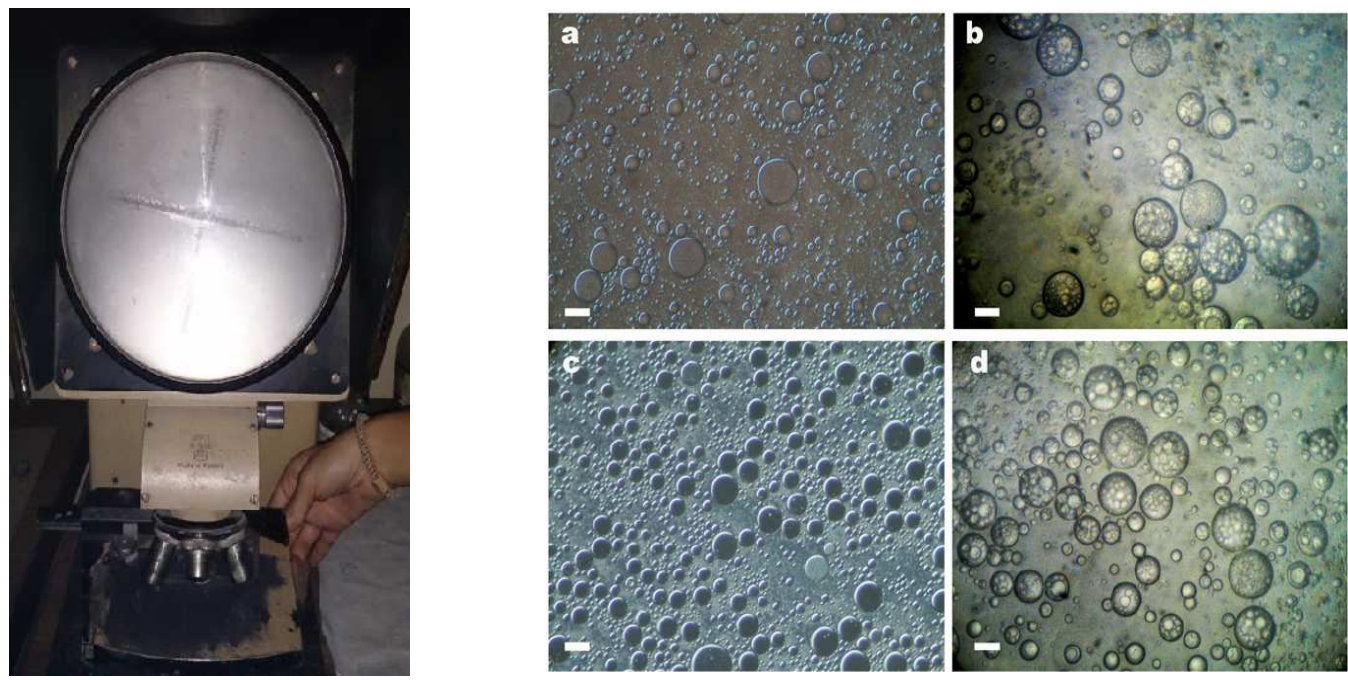

Figure 1: Inverted Microscope and Captured Images

Table 1: Optimization of Ratio of Lemon Grass Oil in Microcapsule Gel

\begin{tabular}{|c|c|c|c|c|c|}
\hline \multirow{2}{*}{$\begin{array}{c}\text { Ratio of } \\
\text { Oil: gum: gelatin }\end{array}$} & \multirow{2}{*}{$\begin{array}{c}\text { Formation of } \\
\text { microcapsules }\end{array}$} & $\begin{array}{c}\text { Size of } \\
\text { microcapsules }\end{array}$ & $\begin{array}{c}\text { Uniformity } \\
\text { in size and } \\
\text { distribution }\end{array}$ & $\begin{array}{c}\text { Wall of } \\
\text { microcapsules }\end{array}$ & Rank \\
\hline $0.5: 4: 4$ & No & - & - & - & - \\
\hline $1: 4: 4$ & No & - & - & - & - \\
\hline $1.5: 4: 4$ & No & - & - & - & - \\
\hline $\mathbf{2 : 4 : 4}$ & Yes & medium & Average & Thick and sharp & I \\
\hline $2.5: 4: 4$ & yes & Small & Average & Very thin & II \\
\hline
\end{tabular}

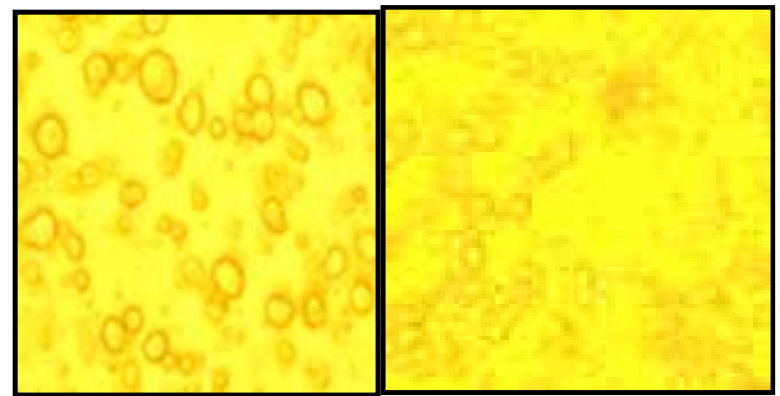

Image-1

Image-2

It is evident from Table-1 and visual assessment of microcapsule gel (Image- 1 to 2) that in case of lemon grass oil microcapsules were formed in only two ratios of oil, gum and gelatin i.e. 2:4:4 and 2.5:4:4. Best capsules were formed at 2:4:4 ratios of oil, gum and gelatin. Hence, ranked $1^{\text {st }}$ indicating medium sized microcapsules with good uniformity in size having thick and sharp walls of capsules. Thus, the ratio four of lemon grass oil was used for further optimization to achieve the best results.

Optimization of Ratio of Gum Acacia in Microcapsule Gel: Gum acacia forms the wall/outer core of the microcapsule and protects the oil from abrasion, sunlight and biodegradation thus provides a controlled release to the oil. Microcapsule gel was prepared using different ratios of gum acacia i.e. 1, 2, 3, 4, and 5. 
The data presented in Table-2 and visual evaluation of microcapsule gel (Image-3 to 5) indicates that microcapsules were formed in only in three ratios only in three ratios i.e. 2:3:4, 2:4:4 and 2:5:4.

Table 2: Optimization of Ratio of Gum Acacia in Microcapsule Gel

\begin{tabular}{|c|c|c|c|c|c|}
\hline & \multicolumn{4}{|c|}{ Parameters } \\
\cline { 3 - 6 } $\begin{array}{c}\text { Lemon grass } \\
\text { oil: gum: } \\
\text { gelatin }\end{array}$ & \multirow{2}{*}{$\begin{array}{c}\text { Formation of } \\
\text { microcapsules }\end{array}$} & $\begin{array}{c}\text { Size of } \\
\text { microcapsules }\end{array}$ & $\begin{array}{c}\text { Uniformity in } \\
\text { size and } \\
\text { distribution }\end{array}$ & $\begin{array}{c}\text { Wall of } \\
\text { microcapsules }\end{array}$ & Rank \\
\hline $2: 1: 4$ & No & - & - & - & - \\
\hline $2: 2: 4$ & No & - & - & - & - \\
\hline $2: 3: 4$ & No & Small & Poor & Very thick & III \\
\hline $2: 4: 4$ & Yes & medium & Average & Thick and sharp & I \\
\hline $2: 5: 4$ & yes & Medium+Large & Average & Thick & II \\
\hline
\end{tabular}

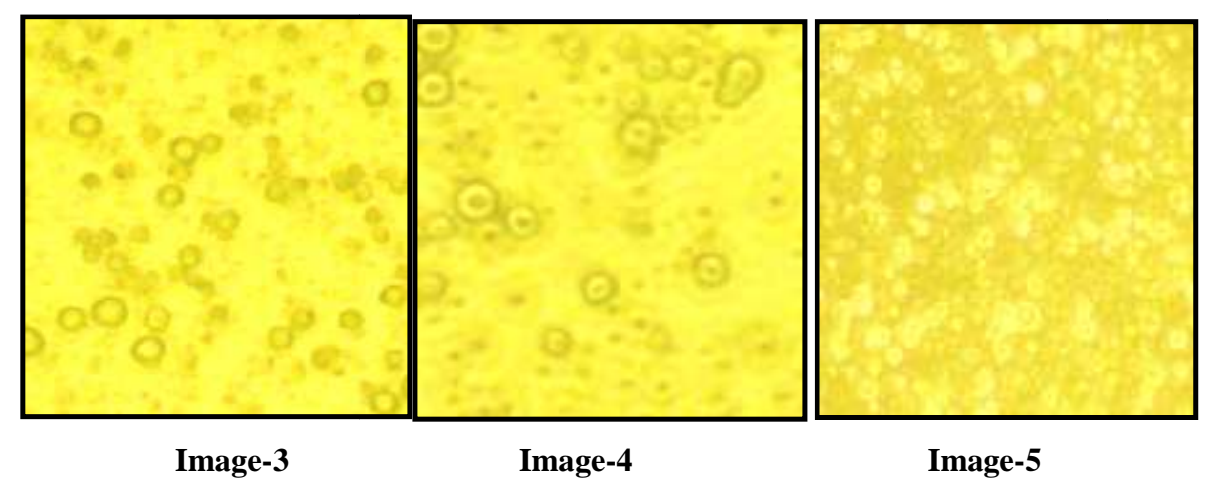

The microcapsules formed in the ratio of 2:4:4 were medium sized, having good uniformity in size and distribution and the walls were also sharp and thick as compared to the capsules formed in the other ratios. Therefore, the ratio 4 was optimized for lemon grass oil.

Optimization of Ratio of Gelatin in Microcapsule Gel: Gelatin is a common ingredient of complex coacervation process and gives best results with gum acacia and essential oils. Microcapsule gel was prepared using different ratios of gelatin i.e. 1, 2, 3, 4 and 5 .

Table 3: Optimization of Ratio of Gelatin in Microcapsule Gel

\begin{tabular}{|c|c|c|c|c|c|}
\hline \multirow{2}{*}{$\begin{array}{c}\text { Ratio of } \\
\text { LM Oil: } \\
\text { Gum: } \\
\text { Gelatin }\end{array}$} & \multirow[b]{2}{*}{$\begin{array}{l}\text { Formation of } \\
\text { Microcapsules }\end{array}$} & \multicolumn{4}{|c|}{ Parameters } \\
\hline & & Size of Microcapsules & $\begin{array}{l}\text { Uniformity } \\
\text { in Size and } \\
\text { Distribution }\end{array}$ & $\begin{array}{c}\text { Wall of } \\
\text { Microcapsules }\end{array}$ & Rank \\
\hline $2: 4: 1$ & No & - & - & - & - \\
\hline $2: 4: 2$ & No & - & - & - & - \\
\hline $2: 4: 3$ & No & - & - & - & - \\
\hline $2: 4: 4$ & Yes & Medium+Small & Average & $\begin{array}{c}\text { Thick and } \\
\text { sharp }\end{array}$ & I \\
\hline $2: 4: 5$ & yes & Medium + Large & Average & Very thick & II \\
\hline
\end{tabular}




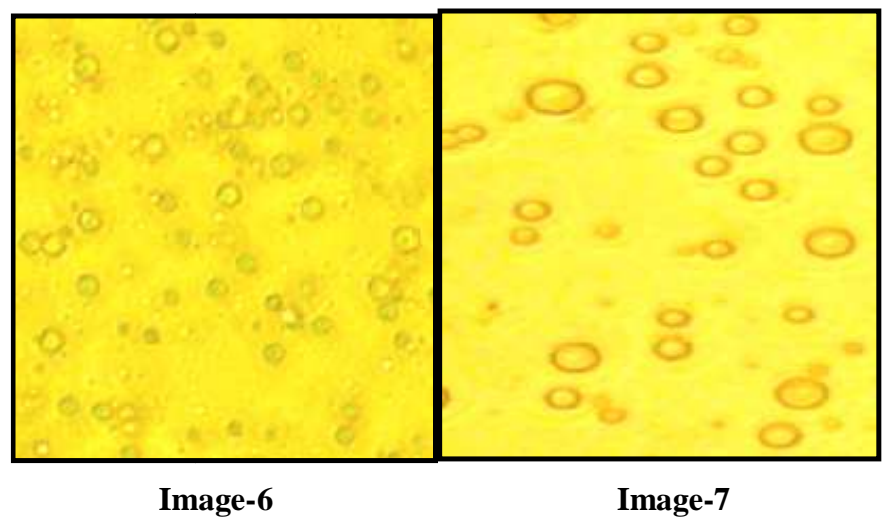

The data presented in Table-3 and visual assessment of microcapsule gel indicates that no microcapsules were formed at ratios of gum, oil and gelatin 2:4:1 2:4:2 and 2:4:3 in case of lemongrass oil. The best microcapsules formed at the ratio of 2:4:4 (Image-6) were medium sized having good uniformity in size and distribution and the walls were thick as compared to the capsules formed at other ratios. Therefore, the ratio 4 of gelatin was optimized for the selected oil.

\section{Optimization of Temperature for Microencapsulation Process}

For optimization of temperature, microencapsulation process was carried out at five different temperatures i.e. 30 , $40,50,60$ and $70^{\circ} \mathrm{C}$.

The data presented in Table- 4 and visual evaluation (Image- 8 to10) reveals that the microcapsules formed at $50^{\circ} \mathrm{C}$ were medium sized, had good uniformity and distribution and the walls were sharp and thick for lemon grass oil.

Table.4: Optimization of Temperature for Microencapsulation of Lemongrass Oil

\begin{tabular}{|c|c|c|c|c|c|}
\hline \multirow[b]{2}{*}{$\begin{array}{l}\text { Temperature } \\
\left({ }^{\circ} \mathrm{C}\right)\end{array}$} & \multirow[b]{2}{*}{$\begin{array}{l}\text { Formation of } \\
\text { Microcapsules }\end{array}$} & \multicolumn{3}{|c|}{ Parameters } & \multirow[b]{2}{*}{ Rank } \\
\hline & & $\begin{array}{c}\text { Size of } \\
\text { Microcapsules }\end{array}$ & $\begin{array}{l}\text { Uniformity } \\
\text { in Size and } \\
\text { Distribution }\end{array}$ & $\begin{array}{c}\text { Wall of } \\
\text { Microcapsules }\end{array}$ & \\
\hline 30 & No & - & - & - & - \\
\hline 40 & Yes & Medium & Average & Thick and Sharp & II \\
\hline 50 & Yes & Medium & Good & Thick and Sharp & $\mathbf{I}$ \\
\hline 60 & Yes & Large & Average & Thick and Sharp & III \\
\hline 70 & No & - & - & - & - \\
\hline
\end{tabular}

Gum:oil:gelatine- 2:2:4

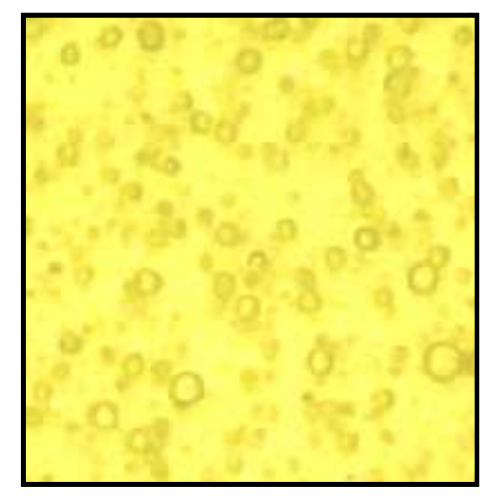

Image-8

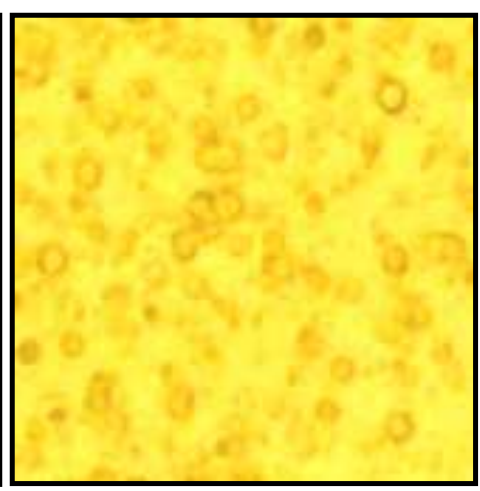

Image-9

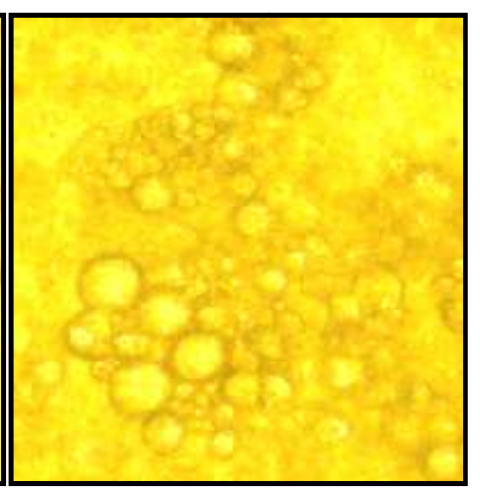

Image-10 
Microcapsules were not formed at temperature $30^{\circ}$ and $70^{\circ} \mathrm{C}$. Hence, $50^{\circ} \mathrm{C}$ temperature was optimized and used for development of essential oil microcapsules.

\section{Optimization of $\mathrm{pH}$ for Microencapsulation Process}

To optimize initial $\mathrm{pH}$ and the final $\mathrm{pH}$, microencapsulation was carried out with optimized ratio of oil:gum:gelatin and temperature. Microcapsule gel was initially started at $\mathrm{pH}$ 4.0, 4.5, 5.0, 5.5, 6.0, 6.5 and 7.0. After the completion of microencapsulation process, the final $\mathrm{pH}$ of the gel was set at 7.0, 7.5, 8.0, 8.5, 9.0 9.5 and 10 .

Table 5: Optimization of Ph for Microencapsulation of Lemon Grass Oil

\begin{tabular}{|c|l|l|l|l|l|}
\hline \multirow{2}{*}{$\begin{array}{c}\text { pH } \\
\text { (Initial / Final }\end{array}$} & \multirow{2}{*}{$\begin{array}{c}\text { Formation of } \\
\text { Microcapsules }\end{array}$} & $\begin{array}{c}\text { Size of } \\
\text { Microcapsules }\end{array}$ & $\begin{array}{c}\text { Uniformity in } \\
\text { Size and } \\
\text { Distribution }\end{array}$ & $\begin{array}{c}\text { Wall of } \\
\text { Microcapsules }\end{array}$ & Rank \\
\hline $4.0 / 8.5$ & Yes & Very Small & Very Poor & Thin & XII \\
\hline $4.0 / 9.0$ & Yes & Small & Poor & Thick & X \\
\hline $4.0 / 9.5$ & Yes & Large & Poor & Very Thick & XI \\
\hline $4.0 / 10.0$ & Yes & Medium+Small & Average & Very Thick & VI \\
\hline $4.5 / 8.5$ & Yes & Medium & Average & Thick & IV \\
\hline $4.5 / 9.0$ & Yes & Medium & Average & Thick and Sharp & II \\
\hline $4.5 / 9.5$ & Yes & Medium & Good & $\begin{array}{l}\text { Thick and } \\
\text { Sharp }\end{array}$ & I \\
\hline $4.5 / 10.0$ & Yes & Medium & Good & Thick & III \\
\hline $5.0 / 8.5$ & Yes & Medium & Average & Very Thick & V \\
\hline $5.0 / 9$ & Yes & $\begin{array}{l}\text { Medium }+ \\
\text { Large }\end{array}$ & Average & Thick & VII \\
\hline $5.0 / 9.5$ & Yes & $\begin{array}{l}\text { Medium }+ \\
\text { Small }\end{array}$ & Average & Very Thin & VIII \\
\hline $5.0 / 10.0$ & Yes & Medium & Average & Thin & IX \\
\hline
\end{tabular}

Gum:oil:gelatin-2:2:4, temperature- $50^{\circ} \mathrm{C}$

As apparent from Table-5 and Image-11, microcapsules formed at initial pH 4.5 and final pH 9.5 were medium sized with uniform distribution having thick and sharp walls in case of clove oil Hence, these $\mathrm{pH}$ values were used for further experimental work as optimum initial and final $\mathrm{pH}$ for microencapsulation process of selected essential oil.

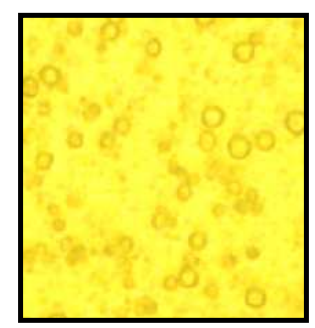

\section{Image.11: Optimization of pH for Microencapsulation}

\section{CONCLUSIONS}

Microencapsulation is mainly used to increase the stability and life of the product being encapsulated, facilitate the manipulation of the product and control its liberation in an adequate time and space Microencapsulation of EOs can protect and prevent the loss of volatile aromatic ingredients and improve the controlled release and stability of this core materials. The findings of the present study revealed that in optimization process of preparation of microcapsules of lemongrass oil, best microcapsules were formed at the optimized ratio 2:4:4 of oil: gum: gelatin, at an optimized $50^{\circ} \mathrm{C}$ 
temperature having initial $\mathrm{pH} 4.5$ and final $\mathrm{pH}$ 9.5. The microcapsules formed with these optimized conditions were observed medium having good uniformity in size and distribution with sharp and thick walls of capsules, these can be effectively used for its wider application in healthcare products for incorporating functional finishes.

\section{REFERENCES}

1. Marcela, F., Lucía, C., Eva, B., David, G., Ángeles, B. and Luis, B. (2015) Microencapsulation of Essential Oils by Interfacial Polimerization Using Polyurea as a Wall Material. Journal of Encapsulation and Adsorption Sciences, 5, 165-177. doi: 10.4236/jeas.2015.54014.

2. Shaaban, H. A. E., El-Ghorab, A. H. and Shibamoto, T. Bioactivity of essential oils and their volatile aroma components: review. J. Essent. Oil Res. 24, 203-212 (2012).

3. Yorgancioglu, A. and Bayramoglu, E. E. Production of cosmetic purpose collagen containing antimicrobial emulsion with certain essential oils. Ind. Crops Prod. 44, 378-382 (2013).

4. Prakash, B., Kedia, A., Mishra, P. K. and Dubey, N. K. Plant essential oils as food preservatives to control moulds, mycotoxin contamination and oxidative deterioration of agri-food commodities - potentials and challenges. Food Control 47, 381-391 (2015).

5. Ammayappan, L. K. Nayak, D. P. Ray, S. Das, and A. K. Roy. 2013. Functional Finishing of Jute Textiles-An Overview in India L. Journal Of Natural Fibers Vol. 10, Iss. 4.

6. Kpoviessi S, Bero J, Agbani P, Gbaguidi F, Kpadonou-Kpoviessi B, Sinsin B, Accrombessi G, Frédérich M, Moudachirou M, Quetin-Leclercq J.2014. Chemical composition, cytotoxicity and in vitro antitrypanosomal and antiplasmodial activity of the essential oils of four Cymbopogon species from Benin.J Ethnopharmacol 151:652-9.

7. Naik MI, Fomda BA, Jaykumar E, Bhat JA. 2010. Antibacterial activity of lemongrass (Cymbopogon citratus) oil against some selected pathogenic bacterias. Asian Pac J Trop Med 3:535-8

8. Costa CARDA, Kohn DO, de Lima VM, Gargano AC, Flório JC, Costa M. 2011. The GABAergic system contributes to the anxiolytic-like effect of essential oil from Cymbopogon citratus(lemongrass). J Ethnopharmacol 137:828-36

9. Gharsallaoui A, Roudaut G, Chambin O, Voilley A, Saurel R. 2007. Applications of spray-drying in microencapsulation of food ingredients: An overview. Food Res Int 40:1107-21.

10. Calvo P, Castaño ÁL, Lozano M, González-Gómez D. 2012. Influence of the microencapsulation on the quality parameters and shelf-life of extra-virgin olive oil encapsulated in the presence of BHT and different capsule wall components. Food Res Int 45:256-61.

11. Fang Z, Bhandari B. 2010. Encapsulation of polyphenols - a review. Trends Food Sci Technol 21:510-23.

12. Bakry, A. M., Abbas, S., Ali, B., Majeed, H., Abouelwafa, M. Y., Mousa, A. and Liang, L. (2016), Microencapsulation of Oils: A Comprehensive Review of Benefits, Techniques, and Applications. Comprehensive reviews in food science and food safety, 15: 143-182. doi:10.1111/1541-4337.12179

13. Berger, R. G. Flavours and Fragrances, pp. 43-86. Springer Science \& Business Media, Heidelberg (2007). 
14. Teli, M. D., Adivarker, R. V. and Kumar, A. 2005. Microencapsulation of disperse dyes by coacervation methods. Journal of Textile Association, 66(1):27-34.

15. https://en.wikipedia.org/wiki/Micro-encapsulation 
